\title{
AdRENAL COLLISION TUMOR: RENAL CARCINOMA METASTASIS \\ WITHIN ADRENAL ADENOMA
}

\section{Roberta Reichert' ${ }^{1}$, Alice Schuch², Gustavo Felipe Luersen²}

\begin{abstract}
Collision tumors are defined as the presence of two contiguous histologically different lesions composed of benign and/or malignant components. They are infrequent entities and have been reported in various organs and systems. The most common type of collision tumor in the adrenal gland is the association of two benign lesions, adenoma and myelolipoma. Modification in image characteristics or unexpected growth of an adrenal tumor previously characterized as a benign lesion should be suspicious for collision tumor with a new aggressive component. In this article, we present a case of renal carcinoma metastasis within a previously known adrenal adenoma.
\end{abstract}

Keywords: Magnetic resonance imaging; adrenal collision tumor; adrenal adenoma; renal cell carcinoma

A 58-year-old female patient, former smoker, was on oncological follow-up due to clear renal cell carcinoma in the right kidney. Total nephrectomy was performed in September 2011. As an incidental finding at that time, the patient also presented a well-defined nodule in the left adrenal gland on a magnetic resonance imaging (MRI) scan in keeping with adenoma and measuring $3.0 \mathrm{~cm}$ in diameter (Figure 1). An abdominal computed tomography (CT) performed in September 2013 showed a slight increase in size of the left adrenal gland nodule, with $3.5 \mathrm{~cm}$ in diameter at this moment. In addition, a small soft tissue density nodule with intense contrast enhancement arose within it, measuring $1.5 \mathrm{~cm}$ (Figure 2). Right adrenal gland and left kidney had usual tomographic appearance. The hypothesis of a metastatic implant within the previously known adrenal adenoma was suggested. A MRI study confirmed the presence of the hypervascular lesion within the left adrenal

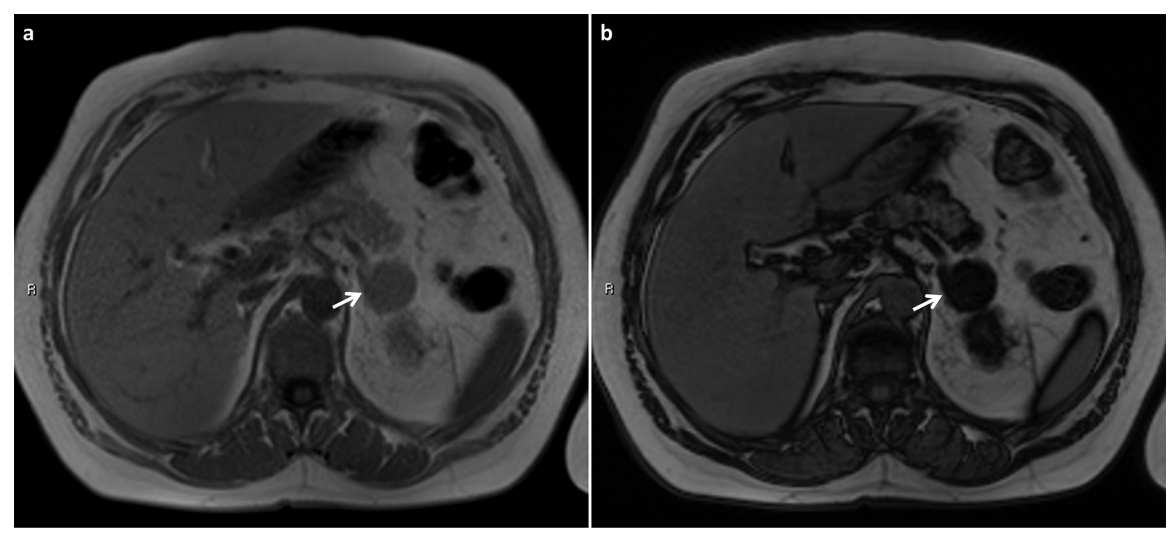

Figure 1: Magnetic resonance imaging (MRI) performed in January 2012. (a) Axial T1-weighted in-phase image shows a well-defined nodule in the left adrenal gland measuring $3.0 \mathrm{~cm}$ in diameter (arrow). (b) Axial T1-weighted out-of-phase image shows a marked and homogeneous decrease in signal intensity of this nodule, indicating the presence of intracellular fat, a finding suggestive of adrenal adenoma (arrow).
Clin Biomed Res. 2015;35(3):169-171

1 Radiology Division, Hospital de Clínicas de Porto Alegre (HCPA). Porto Alegre, RS, Brazil.

2 Radiology Division, Hospital Moinhos de Vento. Porto Alegre, RS, Brazil.

Corresponding author:

Roberta Reichert

E-mail: roberta_reichert@hotmail.com Hospital de Clínicas de Porto Alegre, Serviço de Radiologia

Rua Ramiro Barcelos, 2350.

90035-903, Porto Alegre, RS, Brazil. 
adenoma. The new component showed restriction of water diffusion and absence of signal loss in out-of-phase images, which indicate hypercellularity and lack of intracellular fat, respectively, opposite characteristics compared to those presented by other portions of the adrenal adenoma (Figure 3). Based on these findings, left adrenalectomy was performed in December 2013. In accordance with the
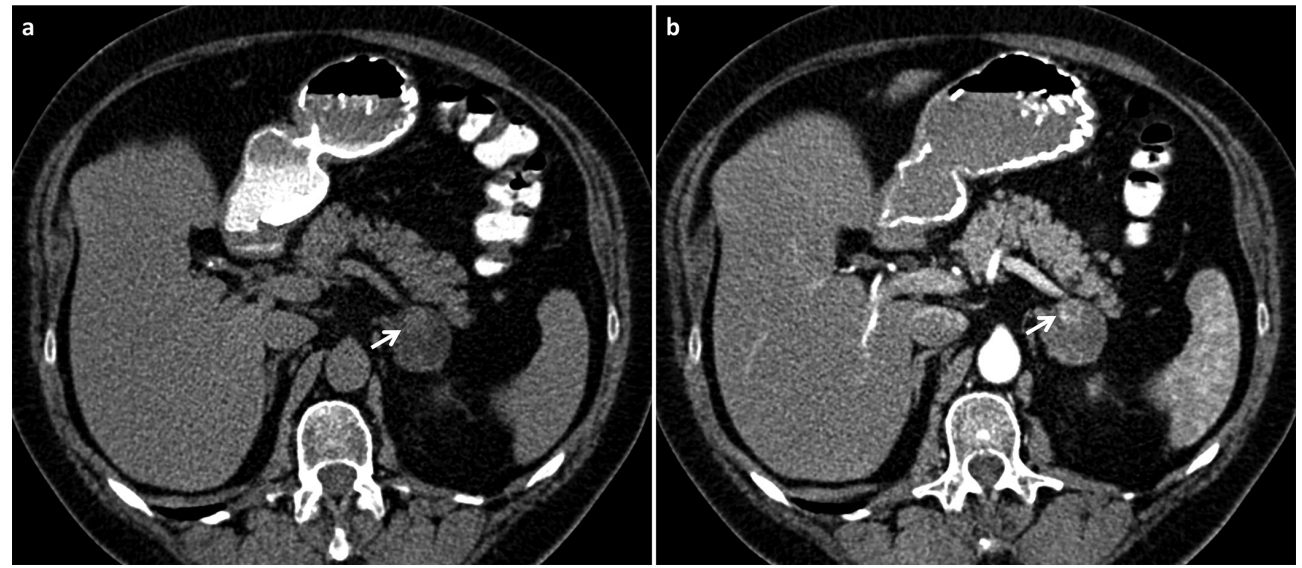

Figure 2: Precontrast (a) and postcontrast (b) computed tomography (CT) performed in September 2013. There was a slight increase in size of the left adrenal gland nodule, which measures $3.5 \mathrm{~cm}$ in diameter at this moment. In addition, a small hypervascular soft tissue density nodule arose within it (arrows). The hypothesis of a metastatic implant within the previously known adrenal adenoma was suggested.
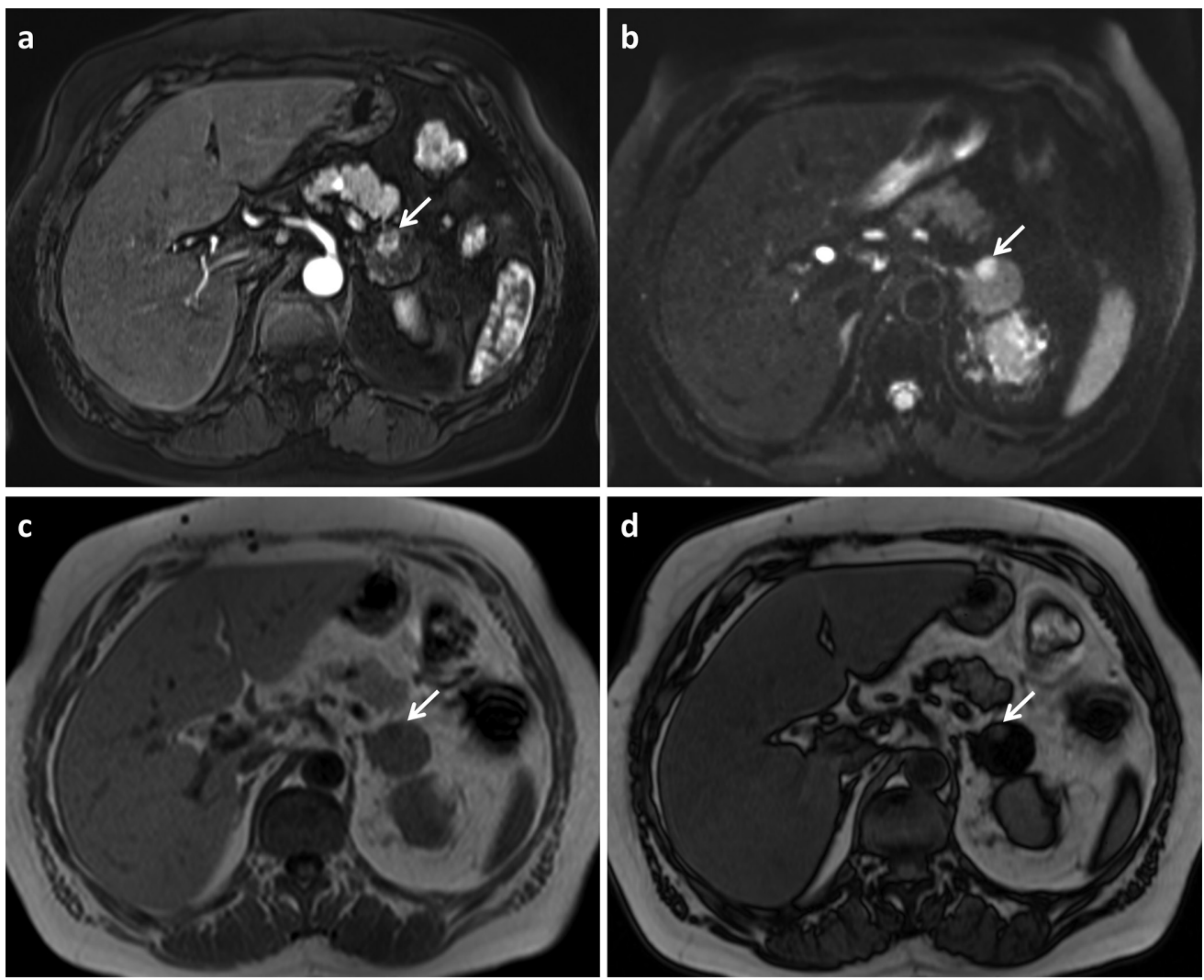

Figure 3: (a) Axial arterial postcontrast fat-saturated T1-weghted magnetic resonance imaging (MRI) confirming the presence of hypervascular lesion within the left adrenal adenoma (arrows). The new nodule showed restriction of water diffusion (b) and absence of signal loss in out-of-phase image (d) in relation to in-phase image (c), opposite characteristics compared to those presented by other portions of the adrenal adenoma. Renal carcinoma metastasis within the adrenal adenoma was confirmed by histopathological study (collision tumor). 
imaging findings, histopathological study described renal cell carcinoma metastasis within the adrenal adenoma, which is indicative of collision tumor. The patient remains under clinical and radiological periodic monitoring. To date, there is no evidence of abdominal recurrence.

Adrenal cortical adenoma is the most common tumor of the adrenal gland, with an estimated prevalence of $1.4 \%$ to $8.9 \%$ based on autopsy series ${ }^{1}$. They are characteristically well-demarcated lesions composed of water and fat, the latter predominantly intracellular ${ }^{1,2}$. Collision tumors are uncommon entities defined by the presence of two contiguous histologically different lesions, described in various locations, such as central nervous system, breast, lung, adrenal gland, and others ${ }^{2,3}$. They may be composed of two benign or two malignant lesions, or a benign tumor with a malignant lesion ${ }^{4}$. In the adrenal gland, the most common type of collision tumor is the association of adenoma and myelolipoma ${ }^{4}$. Adrenal metastatic implants are typically originated by lung carcinoma, breast carcinoma, or melanoma ${ }^{1,3,4}$. CT can show differences in attenuation and enhancement between the lesions ${ }^{1,3}$. The growth of a lesion previously characterized as adrenal adenoma should also be suspicious of collision tumors with a new more aggressive component, such as adrenal metastasis, adrenal carcinoma, or pheochromocytoma ${ }^{3}$. Chemical shift MRI properties can assess the presence of intracellular fat, a feature typically associated with adenomas ${ }^{1-5}$. The absence of signal loss in out-of-phase images in some portion of an adenoma should raise the possibility of secondary neoplastic implants, especially in patients with known extra-adrenal cancer ${ }^{1,2}$. Special attention should be given to renal cell carcinoma: due to varying amounts of cytoplasmic fat, it can present signal loss similar to adenomas $^{5}$. In these cases, other parameters must be considered, such as growth and enhancement kinetics ${ }^{5}$.

\section{Conflicts of interest}

The authors declare no conflict of interest.

Institution where the study was performed: The present study was performed at Hospital Moinhos de Vento.

\section{REFERENCES}

1. Lattin GE JR, Sturgill ED, Tujo CA, Marko J, Sanchez-Maldonado KW, Craig WD, et al. From the radiologic pathology archives: Adrenal tumors and tumor-like conditions in the adult: radiologic-pathologic correlation. Radiographics. 2014;34(3):80529. http://dx.doi.org/10.1148/ rg.343130127. PMid:24819798.

2. Schwartz LH, Macari M, Huvos AG, Panicek DM. Collision tumors of the adrenal gland: demonstration and characterization at MR imaging.
Radiology. 1996;201(3):75760. http://dx.doi.org/10.1148/ radiology.201.3.8939227. PMid:8939227.

3. Tappouni R, DeJohn L. AJR teaching file: enlarging adrenal mass previously characterized as an adenoma. AJR Am J Roentgenol. 2009;192(6 Suppl):S125-7. http:// dx.doi.org/10.2214/AJR.07.7016. PMid:19458099.

4. Katabathina VS, Flaherty E, Kaza R, Ojili V, Chintapalli KN, Prasad
SR. Adrenal collision tumors and their mimics: multimodality imaging findings. Cancer Imaging. 2013;13(4):602-10. http://dx.doi. org/10.1102/1470-7330.2013.0053. PMid:24434021.

5. Piotrowski Z, Tomaszewski JJ, Hartman AL, Edwards K, Uzzo RG. Renal cell carcinoma and an incidental adrenal lesion: adrenal collision tumors. Urology. 2015;85(3):e178. http://dx.doi.org/10.1016/j. urology.2014.12.010. PMid:25733309. 